\title{
TRATAMENTO CIRÚRGICO FILTRANTE DO GLAUCOMA ASSOCIADO AO USO TÓPICO DE ÁCIDO SALICÍLICO EM CÃO
}

\author{
Filtrating surgical treatment of glaucoma associated with \\ topical salicylic acid in dogs
}

Resumo

\author{
Antônio Felipe Paulino de Figueiredo Wouk ${ }^{2}$
}

O tratamento médico para o glaucoma tem apresentado evoluções, porém grande parte dos casos acaba necessitando de intervenção cirúrgica. Os procedimentos cirúrgicos filtrantes estão entre os mais realizados para o tratamento desta afecção e apresentam como determinante do sucesso pós-operatório a modulação cicatricial, uma vez que o orifício de drenagem pode facilmente ser obliterado por uma cicatriz. Muitas drogas foram e continuam sendo testadas no controle da cicatrização, porém ainda não se apresentou um fármaco com alto potencial antifibrótico e baixo risco tóxico. O objetivo principal deste estudo consiste na obtenção de uma formulação tópica de ácido salicílico, precursor do ácido acetilsalicílico, que apresente alto índice de segurança e resultados satisfatórios na modulação da cicatrização no período pós-operatório de cirurgias filtrantes. O colírio de ácido salicílico foi formulado à concentração de $0,3 \%$, atendendo às especificações farmacológicas e foi submetido a um teste de tolerância ocular, no qual se comprovou seu baixo risco tóxico. Após a indução de glaucoma experimental, quatorze cães foram submetidos a trefinação escleral associada a iridectomia periférica e divididos em dois grupos. Instilou-se o colírio de ácido salicílico nos cães tratados e solução de cloreto de sódio 0,9\% nos cães controle. Os grupos foram acompanhados durante 62 dias e avaliados quanto à patência do orifício de filtração. Os resultados demonstraram diferença significativa entre os dois grupos, sendo que o grupo tratado com o colírio de ácido salicílico manteve o orifício patente por mais tempo, demonstrando a eficácia deste produto como modulador da cicatrização e agente antifibrótico. Palavras-chave: Glaucoma, Cirurgia filtrante, Ácido acetilsalicílico, Ácido salicílico.

\section{Abstract}

Medical treatment of glaucoma has evolved, but a substantial part of the cases still require surgical intervention. Filtration surgery is one of the most common procedures used to treat this disturbance. The success of the intervention depends greatly on scar formation control, since the aqueous humour drainage orifice can be easily obliterated by a fibrous scar. Many drugs have been tested in scar formation management. However, a medicine with high antifibrotic potential and low toxicity has not yet been presented. The main object of this study is the elaboration of a topic formulation of salicylic acid, precursory of acetylsalicylic acid, intended to present high safety index and satisfactory results in scar formation control during the post-operative period of filtration surgery for glaucomatous individuals. The experiment was performed using salicylic acid eye drops at a concentration of $0.3 \%$ concentration, meeting ophthalmic pharmacological specifications and submitted to ocular tolerance tests that showed low toxic risk. After the induction of experimental glaucoma in $14 \mathrm{dogs}$, these were submitted to scleral trephination associated with peripheric iridectomy and split into a control group and another group treated with the eye drops. The control group received sodium chloride $0.9 \%$ solution eye drops. The groups were observed for 62 days and evaluated concerning the persistency of the orifice that was created during surgery. Results showed significant difference between the two, as the group treated with salicylic acid presented a patent filtration orifice for longer periods than the control, demonstrating the efficacy of this product as a scar formation control and antifibrotic agent.

Key words: Glaucoma, Filtration surgery, Acetylsalicylic acid, Salicylic acid.

1 Médica Veterinária do Hospital Veterinário do SCA da UFPR; Mestre em Ciências Veterinárias, área de Patologia Animal, Menção Cirurgia e Oftalmologia Veterinária.

2 Doutor, Prof. Titular de Cirurgia e Oftalmologia Veterinária da UFPR e da PUCPR; Membro fundador do Colégio Brasileiro de Oftalmologia Veterinária; Membro Titular do Colégio Latinoamericano de Oftalmologia Veterinária; Certificado de Estudos Superiores de Oftalmologia Veterinária pela Escola de Veterinária de Toulouse-França. 


\section{Introdução e revisão de literatura}

O glaucoma é uma condição patológica que afeta várias estruturas oculares e provoca lesões que estão quase sempre associadas ao aumento da pressão intra-ocular (PIO). Constitui emergência, tanto na medicina humana quanto na veterinária, devido ao alto potencial para provocar cegueira temporária ou permanente. O objetivo maior da terapia antiglaucomatosa é a redução da PIO com a finalidade de evitar a lesão ao nervo óptico (GIONFRIDDO, 1995).

O tratamento médico para esta doença tem apresentado evoluções, mas muitos casos necessitam de tratamento cirúrgico, onde ainda se busca a melhor estratégia. Dentre os procedimentos cirúrgicos, estão aqueles que objetivam aumentar a drenagem do humor aquoso, ou seja, as operações filtrantes. Estas apresentam um alto índice de recidiva do glaucoma, uma vez que o espaço de drenagem construído, em muitos casos é obliterado por uma cicatriz em pouco tempo. Médicos e médicos veterinários anseiam por técnicas cirúrgicas que sejam efetivas por longo prazo e conservem a visão do paciente (GIONFRIDDO, 1995).

Várias drogas estão em teste e são utilizadas para controlar a cicatrização nas cirurgias filtrantes. Entre elas estão a Mitomicina e o 5Fluorouacil, contudo estes fármacos apresentam alguns efeitos colaterais como falta de vascularização no sítio operatório e efeito tóxico sobre o corpo ciliar. Estas alterações podem comprometer algumas estruturas oculares, assim como a visão do paciente (SKUTA, 1996). O ácido salicílico, assim como o ácido acetilsalicílico, é um conhecido agente antiprostaglandinas, que atua também na inibição da agregação plaquetária e apresenta grande potencial queratolítico. Estudos anteriores com o uso intraoperatório de Mitomicina C e ácido acetilsalicílico demonstraram bons resultados deste último como modulador cicatricial e baixo risco tóxico. (WOUK et al, 1999).

Vários tratamentos visando a aumentar a drenagem do humor aquoso têm sido testados em medicina veterinária, dentre eles: ciclodiálise, iridencleise, trepanação córneo-escleral e implantes na câmara anterior (ROBERTS, 1994).

A trepanação córneo-escleral está normalmente associada a iridectomia periférica. A fístula córneo-escleral permite a drenagem do humor aquoso diretamente da câmara anterior para o espaço subconjuntival. A iridectomia periférica é essencial para prevenir a oclusão da fístula por tecido da base da íris. A iridectomia periférica também permite uma comunicação adicional entre as câmaras anterior e posterior (GELATT, 1991; STADES et al, 1999).

Diferenças anatômicas e fisiológicas entre cães e seres humanos explicam o fato de que alguns procedimentos utilizados na medicina humana podem freqüentemente causar complicações quando realizados em cães. Em procedimentos em que a íris e o corpo ciliar são extensivamente manipulados pode ocorrer sangramento intra-ocular incontrolável em cães com conseqüências extremas. O sucesso da intervenção convencional também tem sido limitado devido à uveíte. A uveíte pós-cirúrgica causa uma oclusão dos novos caminhos de drenagem do humor aquoso, freqüentemente em poucos dias, mesmo com o uso de antiinflamatórios (EKESTEN, 1994).

Estudos prévios comparando o uso intraoperatório de mitomicina $\mathrm{C}$ e ácido acetilsalicílico Wouk et al. (1999) demonstraram que a mitomicina C causou graves complicações pós-operatórias como olhos hipotônicos ou bolhas sem filtração adequada, enquanto os olhos tratados com o ácido acetilsalicílico apresentaram-se normotensos e com bolha de filtração satisfatória durante cerca de um ano após a cirurgia. Os mesmos autores sugeriram a realização de outros estudos com o ácido acetilsalicílico como um novo agente antifibrótico e antiinflamatório ocular.

O ácido salićlico só é indicado para uso externo, especialmente em dermatologia, sendo um agente com alto poder irritante para a mucosa. O salicilato de metila é também reservado para uso tópico, em caso de dores musculares ou articulares. No uso sistêmico, por via oral, empregam-se o salicilato de sódio e a aspirina (LEME et al, 1994).

O ácido salicílico aplicado topicamente como agente ceratolítico é associado ao ácido benzóico com freqüência, no tratamento de epidermofitoses. O ácido salicílico associado ao colódio (10 a 20\%) é utilizado na remoção de calos e verrugas. Associado a talco (2 a 3\%) pode ser utilizado na hiperidrose (SAKATE; SUDO, 1994). 


\section{Material e método}

\section{Formulação do colírio de ácido salicílico a 0,3\%}

Para que os estudos sobre a eficácia do ácido salić́lico como agente antifibrótico pudessem ser iniciados, foi necessária a obtenção de uma formulação tópica deste produto que fosse segura, ou seja, que não apresentasse potencial deletério às estruturas oculares e desse modo, após a síntese do colírio, o primeiro passo foi a realização de um teste de toxicidade aguda em olhos sadios, visando a sua utilização em olhos doentes, nos quais o limiar inflamatório é muito menor.

O colírio de ácido salicílico foi desenvolvido nos laboratórios da Indústria Farmacêutica da Pontifícia Universidade Católica do Paraná, atendendo às especificações bioquímicas e farmacológicas necessárias à sua formulação. Optou-se pela síntese de um colírio de ácido salicílico por este ser mais estável que o ácido acetilsalicílico e por possuir maior potencial como queratolítico.

A precisão na composição foi respeitada, garantindo-se a concentração de $3 \mathrm{mg}$ de ácido salicílico em cada um ml do colírio (solução a 0,3\%, máximo conseguido de forma estável). O colírio foi formulado em veículo oleoso (óleo de milho), conferindo maior viscosidade e, conseqüentemente, um tempo de contato mais prolongado com o olho do paciente. Realizaram-se testes de isotonicidade e esterilidade, propriedades indispensáveis a qualquer medicamento de uso ocular.

\section{Teste de toxicidade}

Obtida a formulação tópica de ácido salicílico, realizou-se um teste de toxicidade ocular aguda com o colírio na concentração de $0,3 \%$. Foram utilizados quinze ratos Wistar provenientes do biotério do Centro Politécnico da Universidade Federal do Paraná; quatorze cães, sem raça definida, provenientes do Canil Municipal de Curitiba; três gatos, sem raça definida de proprietários particulares e vinte coelhos de propriedade de um criatório particular. Em todos os exemplares foi instilada uma gota do colírio de ácido salicílico $0,3 \%$ no olho direito, permanecendo o olho esquerdo como controle. Os parâmetros avaliados foram a ocorrência de quemose, blefarospasmo, fotofobia, edema de córnea, modificações na co- loração da íris, no diâmetro pupilar e do aspecto da câmara anterior. Os olhos foram examinados com oftalmoscópio direto e lâmpada de fenda durante seis horas em média. Entre todos os indivíduos testados, cinco ratos apresentaram episódios de blefarospasmo graduado como leve e dois gatos blefarospasmo e fotofobia graduados de leve a moderado. Os cães e coelhos submetidos ao teste não apresentaram qualquer alteração.

\section{Indução de glaucoma experimental}

Foram utilizados 14 cães sadios, com peso médio de $7 \mathrm{~kg}$, sete machos e sete fêmeas, provenientes do serviço de busca e apreensão da Prefeitura Municipal de São José dos Pinhais. Os cães passaram por um período de adaptação de quinze dias antes do início do experimento, quando foram desverminados com Nitroscanato na dose recomendada pelo fabricante e imunizados contra cinomose, parvovirose, leptospirose, coronavirose, parainfluenza e hepatite viral através da aplicação de vacina polivalente. Os animais foram mantidos em canis individuais durante todo o experimento, recebendo alimentação à base de ração comercial e água fresca à vontade.

Para a indução de glaucoma utilizou-se o modelo desenvolvido por Wouk et al (1999) onde uma solução saturada de grafite é injetada na câmara anterior provocando a obliteração do ângulo iridocorneano e, por conseqüência, a elevação da pressão intra-ocular. Os cães foram tranqüilizados utilizando cloridrato de xilazina a $2 \%$ na dose de 1 $\mathrm{mg} / \mathrm{kg}$ administrada por via intramuscular e, sob anestesia tópica com colírio de proximetacaína e pomada anestésica de lidocaína e prilocaína, realizou-se punção da câmara anterior do olho direito com agulha de calibre 13 X 4,5 e injetou-se um volume médio de $1 \mathrm{ml}$ da solução supersaturada de partículas de grafite (Figura 1). A pressão intra-Ocular dos animais foi avaliada durante as 48 horas seguintes por meio de tonometria por aplanação.

Após um período de 48 horas, todos os animais estavam com a pressão intra-ocular acima de $35 \mathrm{mmHg}$ e alguns deles já manifestavam sinais característicos de glaucoma como dor ocular importante, edema de córnea e vasos episclerais engurgitados. Visto que a pressão intra-ocular manteve-se constante durante as 24 horas que se seguiram, os animais foram submetidos à cirurgia filtrante. 


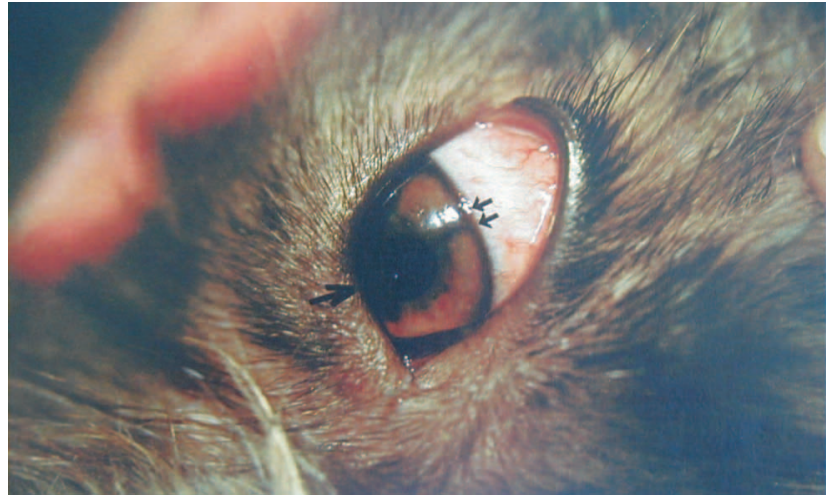

FIGURA 1. Cão, olho direito, aspecto após injeção intracameral de solução supersaturada de grafite. Notar o importante depósito no aspecto ventral da câmara anterior (posição entre $5 \mathrm{~h}$ e 9h), bem como o "trajeto" da solução sobre a face anterior do bordo dorsal da íris (posição de 12h).

\section{Cirurgias filtrantes e tratamento antifibrótico}

Com relação à escolha da técnica cirúrgica, foram selecionadas duas técnicas (incisão cauterizada e trefinação escleral) que foram amplamente testadas em casos clínicos no período préexperimental. A técnica de incisão cauterizada demonstrou estar mais relacionada à ocorrência de fibrose no sítio operatório e, conseqüentemente, obliteração do orifício de drenagem e recorrência dos sinais clínicos Por esse motivo, optou-se por padronizar a técnica cirúrgica e todos os cães foram submetidos a trefinação escleral associada a iridectomia periférica (Figura 2).

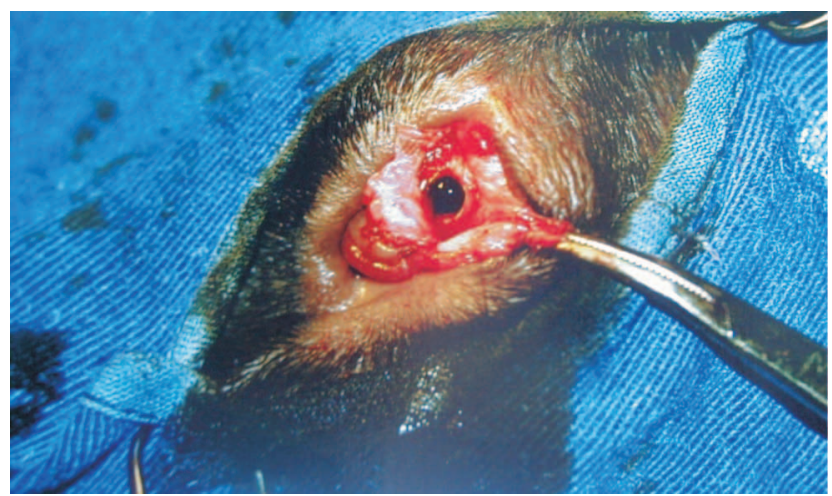

FIGURA 2. Após trefinação escleral em posição de $12 \mathrm{~h}$ e remoção do retalho escleral, no centro do defeito percebe-se o tecido iriano protruído.
A medicação pré-anestésica utilizada foi o sulfato de atropina na dose de $0,04 \mathrm{mg} / \mathrm{kg}$, administrado por via subcutânea, quinze minutos antes da indução anestésica e para a anestesia utilizou-se a cloridrato de quetamina como agente dissociativo na dose de $12 \mathrm{mg} / \mathrm{kg}$ associada a cloridrato de xilazina na dose de $1 \mathrm{mg} / \mathrm{kg}$, ambas administradas por via intramuscular. Com a finalidade de evitar a ocorrência de efeitos indesejáveis da quetamina e para prolongar o tempo anestésico utilizou-se ainda um benzodiazepínico por via intravenosa em associação aos demais fármacos.

Após a anestesia, preparou-se o campo operatório para intervenção cirúrgica asséptica. O olho direito de cada animal foi submetido a trefinação escleral associada a iridectomia periférica. Baseada na técnica descrita por Gelatt (1991), criouse um flap conjuntival de base límbica de cerca de $5 \times 6 \mathrm{~mm}$ e através do deslocamento rostral desta porção de conjuntiva bulbar expôs-se a região límbica. Utilizando-se uma trefina (punch para biópsia) de $4 \mathrm{~mm}$ de diâmetro foi construído um orifício através da esclera, em sua junção com a córnea na posição de 12 horas. O retalho de esclera foi removido e a base da íris, que pôde ser visualizada através do orifício criado, foi pinçada e incisada. A fístula foi recoberta com o tecido conjuntival que havia sido rebatido, através de sutura contínua simples com fio absorvível Categute simples de fino calibre (6-0). Com estes procedimentos fica construída a fístula por onde será drenado o humor aquoso, promovendo a diminuição da pressão intra-ocular. O deslocamento desta porção de conjuntiva bulbar que está posicionada sobre a fístula, causado pela passagem do humor aquoso, promove o que se denomina "bolha de filtração".

Durante os primeiros sete dias de pósoperatório todos os animais tiveram seus olhos operados tratados com pomada oftálmica de Ciprofloxacina para prevenir a ocorrência de infecção no sítio operatório.

Após a realização das cirurgias, os animais foram separados em dois grupos. O primeiro grupo, denominado grupo controle, foi constituído por seis animais e estes foram submetidos à instilação de uma gota de solução de cloreto de sódio na concentração de $0,9 \%$, no olho direito, três vezes ao dia, durante 62 dias. O segundo grupo, denominado grupo tratado, foi constituído por oito animais e nestes, instilou-se uma gota do colírio de ácido salicílico a 0,3\%, na mesma freqüên- 
cia, durante o mesmo período, também no olho direito.

Os animais foram avaliados diariamente através de exame físico, oftalmoscopia direta e avaliação da patência da bolha de filtração. Este último parâmetro foi graduado com a finalidade de quantificar, mesmo que indiretamente, a ocorrência de fibrose no sítio operatório e avaliar a eficácia do ácido salicílico como agente queratolítico. A graduação se deu da seguinte forma: zero para ausência de "bolha" de filtração, + para pequena filtração, ++ para filtração moderada e +++ para filtração adequada.

Para a avaliação dos resultados recorreuse à análise descritiva dos dados através de tabelas, quadros e gráficos. Para a comprovação do objetivo levantado neste trabalho foi utilizado o teste paramétrico "t de Student" (através do software "Primer of Biostatistics") para amostras independentes. O nível de significância (probabilidade de significância) mínimo adotado foi de 5\% $(0,05)$.

\section{Resultados}

\section{Descrição dos parâmetros avaliados}

Os animais dos grupos controle e tratado manifestaram uma série de alterações oculares durante o período de observação. Estas alterações foram associadas tanto ao próprio quadro clínico do glaucoma, quanto à intervenção cirúrgica. Os sinais mais evidentes foram fotofobia, opacidade corneana e hiperemia conjuntival.

A fotofobia foi sinal clínico evidente em todos os cães e se estendeu por um período máximo de vinte dias pós-cirurgia (média de 10 dias), sendo que os cães procuravam cerrar as pálpebras e evitar a incidência de luz nos olhos operados.

As conjuntivas dos olhos que sofreram intervenção cirúrgica permaneceram hiperêmicas durante cerca de 15 dias, quadro que foi acompanhado de secreção de aspecto mucoso em quantidade moderada.

A opacidade corneana foi o sinal que mais variou entre os animais, sendo que alguns deles já apresentavam córnea clara no vigésimo dia póscirurgia e outros permaneceram com opacidade até o último dia do experimento.

A patência da bolha de filtração foi o parâmetro mais importante por estar intimamente correlacionado com a eficácia do procedimento filtrante associada ao uso do agente antifibrótico e por isso foi quantificado. O fluxo do humor aquoso só ocorre se a fístula estiver permitindo a sua passagem da câmara anterior para o espaço subconjuntival e isto depende dos processos cicatriciais que ocorrem no sítio operatório.

O gráfico 1 relaciona os graus de filtração nos cães controle e tratados com o período pós-operatório.

GRÁFICO - 1 Número médio de dias em relação ao grau de filtração nos grupos em estudo.

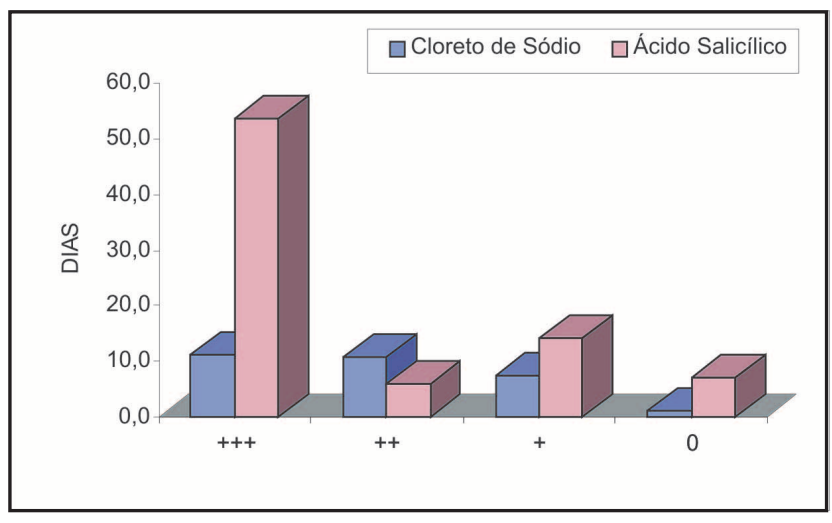

Também foi observado maior porcentual do grau de filtração +++ no grupo tratado com o Ácido Salicílico $(36,5 \pm 7,2$ x 86,3 $\pm 22,9)(\mathrm{p}<0,0001)$ (Gráfico 2).

GRÁFICO - 2 Número médio de dias (porcentual) em relação ao grau de filtração nos grupos em estudo.

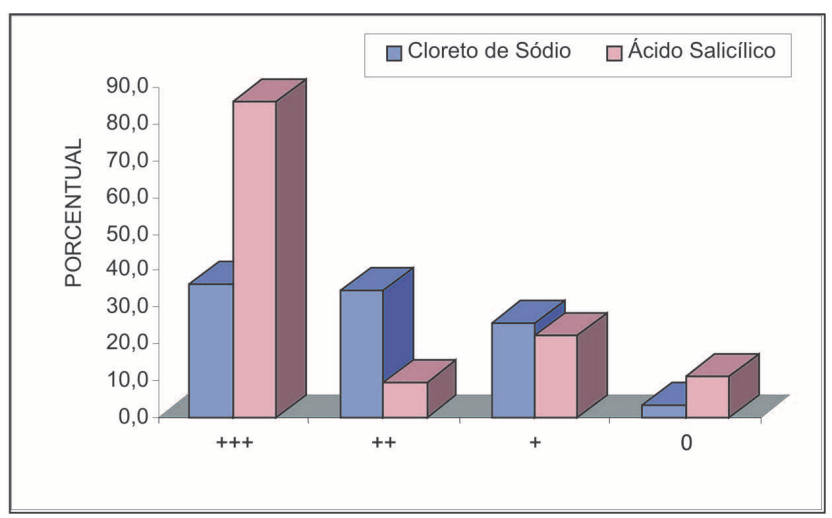




\section{Discussão}

Em cães, as intervenções cirúrgicas filtrantes foram efetivas em vários estudos anteriores Tinsley e Betts (1994); Hakanson (1996) e Garcia-Sanchez et al (1998), porém sua maior complicação consiste na obliteração do orifício de drenagem por uma cicatriz fibrosa (GIONFRIDDO, 1995). Com base neste fato e, seguindo a sugestão de vários autores, Goddard, (1996); Khaw (1996); Lee (1996); Skuta (1996) e Wouk et al (1999), decidiu-se, no presente estudo, pela busca de um agente queratolítico e inibidor da cicatrização para ser utilizado no pós-operatório das operações filtrantes, onde vários antimitóticos já demonstraram resultados por vezes pobres ou nocivos (HYUNG et al, 1996; IGARASHI et al, 1996; SANDERS et al, 1996; ZIEL; JOHNSTONE, 1996).

Em estudos anteriores Wouk et al (1999), o ácido acetilsalicílico demonstrou bom potencial antifibrótico e baixo risco tóxico. Diante destes resultados animadores, decidiu-se obter uma formulação ocular desta substância para ser utilizada como inibidor tópico da cicatrização. Segundo Kadar (1991), os salicilatos administrados sistemicamente distribuem-se de modo desigual pelo organismo, verificando-se níveis pequenos destes compostos em alguns locais como cérebro, líquido cefalorraquidiano, músculo, intestino, cristalino, sêmen e humor aquoso, reafirmando a necessidade de obtenção de uma formulação de uso local. Já no início das pesquisas, observou-se que o ácido acetilsalicílico é extremamente instável em água, além de higroscópico, enquanto que o ácido salicílico, outra substância da classe dos salicilatos, possui baixa hidrólise em água e apresenta pH $(4,5)$ semelhante ao do ácido acetilsalicílico (5,0 a 5,5). Adicionalmente, devido ao fato do ácido salicílico ser considerado um queratolítico e antifibrótico mais potente, optou-se pela escolha desta substância para a formulação do colírio. A concentração máxima obtida e estável foi a de 0,3\%.

O modelo experimental de glaucoma através da injeção de partículas de grafite na câmara anterior demonstrou mais uma vez ser efetivo. Este modelo produziu em todos os animais o colapso da fenda ciliar, mimetizando o glaucoma de ângulo fechado. Nas últimas décadas muito já se pesquisou sobre modelos animais adequados a esta finalidade (LEE et al, 1987). Os mais recentemente desenvolvidos foram o de fotocoagulação a "laser" de argônio da trama trabecular e mediante injeção de microesferas de látex na câmara anterior de olhos de macacos, Weber; Zelenak (1996), porém estas técnicas têm como inconveniente o alto custo.

Os cães nos quais se produziu glaucoma experimental demonstraram alguns sinais de dor e desconforto, fato já esperado, pois o modelo utilizado, conforme relatado por Wouk et al (1999), caracteriza-se por produzir, nas fases iniciais, um quadro de uveíte anterior asséptica, de fundo mecânico e antigênico. Este fato, aliado à resposta inflamatória gerada pela própria intervenção cirúrgica, foi a provável causa dos sinais manifestados.

Com relação ao teste de toxicidade, o colírio de ácido salicílico 0,3\% mostrou-se praticamente inerte às estruturas oculares, visto que em todos os animais testados ocorreram apenas episódios de blefarospasmo e fotofobia. Tais alterações podem ter sido provocadas pelas características físicas do colírio, como a alta viscosidade, ou ainda, associada à reação individual, notadamente em gatos. A acentuada viscosidade do colírio faz com que sua distribuição sobre o olho leve maior tempo e isto pode resultar em movimentos palpebrais mais freqüentes. Segundo Stades et al (1999), a estimulação da córnea é freqüentemente aumentada pelo mecanismo de piscar das pálpebras e estes estímulos podem levar à maior sensibilidade dolorosa das camadas superficiais da córnea e fotofobia. Os coelhos, animais comumente utilizados em testes na área de cosmetologia por apresentarem maior sensibilidade, não apresentaram qualquer alteração nos parâmetros, assim como os cães. Isto reforça a teoria de que as alterações observadas nos outros animais se devem a propriedades físicas do colírio associadas à reação dos indivíduos à aplicação.

A técnica cirúrgica de trefinação escleral associada a iridectomia periférica trouxe resultados satisfatórios, uma vez que permitiu a construção de uma fístula de drenagem de tamanho adequado para a manutenção da bolha de filtração. Além disso, esta técnica provou ser de fácil realização, exigindo mínimo material especializado e conhecimentos cirúrgicos gerais. Sendo assim, permite que cirurgiões ve- 
terinários sem treinamento microcirúrgico possam oferecer conforto a animais glaucomatosos. Kural et al (1995a; 1995b) citaram que os objetivos da terapia antiglaucomatosa são garantir o conforto do animal, recuperar e manter a visão, tendo o proprietário dois prognósticos independentes: um para a manutenção da visão e outro para a integridade do globo ocular.

Como reafirmado por Lee (1996), o sucesso da cirurgia filtrante para o glaucoma está totalmente vinculado à modulação da resposta cicatricial. No presente trabalho, o ácido salicílico demonstrou forte ação queratolítica e de inibição cicatricial, comprovada pela diferença significativa no período de manutenção de patência da bolha de filtração entre os grupos controle e tratados. Sendo o cão um modelo crítico de testes para cirurgias filtrantes do glaucoma (pela intensa fibroplasia que promove um fechamento rápido das fístulas cirúrgicas), os resultados são ainda mais evidentes.

Slatter (1990) relatou que um decréscimo na pressão sangüínea resultará também em um decréscimo na pressão intra-ocular, em contrapartida, Linden e Alm (2000) confirmam que o ácido acetilsalicílico administrado por via oral não afeta significativamente a pressão intra-ocular em indivíduos glaucomatosos. Isto reforça o fato de que o efeito do ácido acetilsalicílico em estudo anterior, Wouk et al, (1999) e do ácido salicílico neste estudo foi como agente queratolítico e inibidor da cicatrização, permitindo a patência da bolha de filtração no período pósoperatório da cirurgia filtrante.

\section{Conclusões}

O trabalho desenvolvido reafirmou a importância do modelo experimental de glaucoma no estudo desta doença, permitindo que se desenvolvam novas soluções para as dificuldades encontradas até hoje no seu tratamento.

A técnica cirúrgica de trefinação escleral aqui empregada proporcionou um grau de filtração adequado por longo período, com mínimo trauma tecidual e demandou poucos cui- dados pós-operatórios, sendo assim uma boa alternativa para o tratamento cirúrgico do glaucoma de ângulo fechado em cães.

O ácido salicílico a 0,3\%, utilizado topicamente sob a forma de colírio, é eficaz e seguro como agente queratolítico e modulador cicatricial nas intervenções cirúrgicas filtrantes do glaucoma em cães, porque manteve a patência da bolha de filtração por longos períodos e porque controla a inflamação pós-operatória sem causar danos às estruturas oculares.

Os resultados obtidos no presente experimento são bastante animadores e oferecem base para uma série de estudos com o ácido salicílico no tratamento cirúrgico do glaucoma e outras condições inflamatórias do olho tanto em medicina veterinária quanto na oftalmologia humana.

\section{Referências}

EKESTEN, B. Surgical treatment of canine glaucomas. Svensk veterinärtidning, v. 46, n. 2 , p. 67-70, 1994.

GARCIA-SANCHEZ, G. A.; BROOKS, D. E.; GELATT, K. N.; KUBILIS, P. S.; GIL, F.; WITHLEY, R. D. Evaluation of valved and non valved gonioimplants in 83 eyes of 65 dogs with glaucoma. Anim. Eye Res. v. 17, n. 1-2, p. 9-16, 1998.

GELATT, Kirk N. Veterinary ophthalmology. 2. ed. Philadelphia : Lea \& Febiger, 1991. 765 p.

GIONFRIDDO, J. R. Recognizing and managing acute and chronic cases of glaucoma. Symposium on red eye in small animals. Veterinary Medicine, Lenexa, KS, p. 265-275, mar. 1995.

GODDARD, D. Mechanisms of inflamatory fibrosis in glaucoma. Investigative Ophtalmology \& Visual Science, Philadelphia, PA, v. 37, n. 3, s-423, fev. 15, 1996.

HÅKANSON, Nils Wallin. Extraorbital diversion of aqueous in the treatment of glaucoma in the dog: a pilot study including two recipient sites. Veterinary \& Comparative Ophthalmology, v. 6, n. 2, p. 82-90, 1996. 
HYUNG, S. M. ; CHOI, M. Y.; JEAN, W. C. Effects of postoperative mitomycin $\mathrm{C}$ eyedrop on trabeculectomy in refractory glaucoma patients. Invetigative Ophtalmology \& Visual Science, Philadelphia, PA, v. 37, n. 3, s-24, fev. 15, 1996.

IGARASHI, S.; SIMMONS, R. B.; IGARASHI, H.; MONTENEGRO, M. H. KASAHARA, N.; YOSHIDA, A.; SIMMONS, R. J. Use of trans conjunctival mitomycin $\mathrm{C}$ for internal revision of glaucoma filtration surgery. Investigative Ophtalmology \& Visual Science, Philadelphia, PA, v. 37, n. 3, s-423, fev. 15, 1996.

KADAR, D. Analgésicos antiinflamatórios. In: KALANT, H.; ROSCHLAU, W. H. E. Princípios de farmacologia médica. 5. ed. Rio de Janeiro RJ: Guanabara Koogan, 1991. p. 264-273.

KHAW, P. T. Animal models of wound healing: lessons from the laboratory to the clinic. Investigative Ophtalmology \& Visual Science. Philadelphia, PA, v. 37, n. 3, s-422, fev.15, 1996.

KURAL, Elinka; LINDLEY, Denise; KROHNE, Sheryl. Canine glaucoma part I. The compendium continuing education. v. 17, n. 8, p 1017-1026, 1995a.

Canine glaucoma part II. The compendium continuing education, v. 17, n. 10, p 1253-1265, 1995b.

LEE, D. A. Animal models and cellular studies of wound healing. Investigative Ophtalmology \& Visual Science, Philadelphia, PA, v. 37, n. 3, s-422, fev.15, 1996b.

LEME, J. Garcia; OliveIRA, J. C. Ramos; SANNOMIYA, Paulina. Drogas antiinflamatórias. In: SILVA, Penildon. Farmacologia. 4. ed. Rio de Janeiro RJ: Guanabara Koogan, 1994. p. 532-546.

LINDEN, C.; ALM A. Acetylsalicylic acid does not reduce the intraocular pressure variation in ocular hypertension or glaucoma. Exp. Eye Res. Mar. 2000.

ROBERTS, Steven M. Glaucoma in companion animals: current management and new trends. California Veterinarian. v. 48, n. 1, p. 9-16, 1994.
SAKATE, Minoru; SUDO, Lia Siguemi. Analgésicos antipiréticos. In: ZANINI, Antonio Carlos; OGA, Seizi. Farmacologia aplicada. 5 ed. São Paulo SP: Atheneu, 1994. p. 252-256.

SANDERS, S. P.; CANTOR, L. B. ; DOBLER, A. A.; HOOP, J. S.; SPONSEL, W.E. Mitomycin $\mathrm{C}$ in complicated trabeculectomy: a prospective comparison of 0,2 to $0,4 \mathrm{mg} / \mathrm{cc}$. Investigative Ophtalmology \& Visual Science, Philadelphia, PA, v. 37, n. 3, s-25, fev.15, 1996.

SKUTA, G. L. Adjunctive mitomycin in glaucoma filtering surgery. Investigative Ophtalmology \& Visual Science, Philadelphia, PA, v. 37, n. 3, s-422, fev.15, 1996.

SLATTER, Douglas. Fundamentals of Veterinary Ophthalmology. 2. ed. Philadelphia : W. B. Saunders, 1990. 630 p.

STADES, Frans C.; BOEVÉ, Michael H.; NEUMANN, Willy; WYMAN, Milton. Fundamentos de oftalmologia Veterinária. São Paulo SP: Manole, 1999. 204 p.

TINSLEY, David M; BETTS, Daniel M. Clinical experience with a glaucoma drainage device in dogs. Veterinary \& Comparative Ophthalmology, v. 2, n. 2, p. 77-84, 1994.

WEBER, A. J.; ZELENAK, D. Experimental glaucoma model in the primate eye induced by injection of latex microspheres into the anterior chamber. Investigative Ophtalmology \& Visual Science, Philadelphia, PA, v. 37, n. 3, s-815, fev.15, 1996.

WOUK et al. Novo modelo experimental de glaucoma em cão para o estudo da cicatrização após cirurgia filtrante associada ao uso de agente antifibrótico. Arch. Vet. Science, Curitiba, Brazil, v.4, n.1, p. 103-109, 1999.

XALATAN: Latanoprost. USA: Pharmacia \& Upjohn Company, 2000. Bula.

ZIEL, C. J. JOHNSTONE, M. A. Combined phacoemulsification and trabeculectomy with mitomycin and postoperative 5-fluouracil (5-FU). Eye Clinic of Wisconsin, Wausau, WI. Investigative Ophtalmology \& Visual Science, Philadelphia, PA, v. 37, n. 3, fev.15, 1996. 